\title{
ANALYSIS OF PERFORMANCE AND POLLUTANT CHARACTERISTICS OF CI ENGINE USING THE MIXTURE OF DIESEL
}

\author{
AND EUCALYPTUS OIL \\ KARIKALAN. L $^{1} \&$ VETRIVEL. $A^{2}$ \\ ${ }^{l}$ Associate Professor, Department of Automobile Engineering, VELS Institute of Science, Technology \& \\ Advanced Studies, Chennai, Tamil Nadu, India \\ ${ }^{2}$ PG Student, Department of Automobile Engineering, VELS Institute of Science, Technology \& \\ Advanced Studies, Chennai, Tamil Nadu, India
}

\begin{abstract}
The present fossil fuel crunch and increasing vehicle numbers made us think of alternative fuels. The abundance of the fossil fuels is expected to be exhaust in another 20-30 years. The cost of the fossil fuels is day by day increasing in India and also the emission from these fuels increases the air pollution. With keeping in view of all the above-said points, it is made us think of alternative fuels for all Combustion Ignition Engines. The present investigation evaluates Eucalyptus oil mixed with diesel in a CI engine. A single cylinder CI Engine adapted to investigate the BSFC, BTE, Combustion and Emission characteristics. In this study, Eucalyptus oil is mixed with diesel fuel as the substitute in diesel Engine and performs various tests and evaluates its performance. The results were compared with standard diesel.
\end{abstract}

KEYWORDS: Engine, Diesel, Eucalyptus Oil, Emission, Combustion \& Analysis

Received: Mar 22, 2018; Accepted: Apr 12, 2018; Published: Apr 28, 2018; Paper Id.: IJMPERDJUN201823

\section{INTRODUCTION}

The gasoline fuel declining and fuel price hikes have created a severe effect on the transport segments, also on the domestic and global economy [1-3]. The significance of biodiesel rises progressively owing to the exhaustion of petroleum assets and progresses in environmental concerns. Plant oils are ecologically responsible and it might offer a viable standby for diesel as these are renewable in the countryside. Several non-edible oils, such as Mahua, Neem, Rubber seed, jatropha, waste cooking and cottonseed oils, are examined for their aptness to $\mathrm{CI}$ engine. The foremost difficulty of the biodiesel is its higher making cost owing to the higher price of plant oil, which comes around $75 \%$ of the biodiesel making. The esters of plant oil are biodegradable, non-toxic and renewable alternate fuel getting responsiveness [4-7]. The usage of raw plant oil in engines with no alteration costs deprived performance and lead to engine components wear [8]. The high viscosity and low calorific value of esters leads to the lesser BTE and poor engine performances.

In the modern society having much advancement in technology, there are also some issues relating to an alternate source of fuel to sustain the transportation sector for the future generation. However our dependence is on diesel and petroleum for fuelling the transportation sector and if this continues then this could threaten our energy resource, affect our economy and even affect our environment so badly that it may even take hundreds of years for 
a seed to sprout [9-12]. Thus we are in search of an alternate source of fuel to have a sustainable economy. This is possible with the use of biodiesel which is a renewable basis of energy. Though it is not possible to run a DI diesel Engine on $100 \%$ biodiesel like jatropha with no major alterations in the presently available engine, when blended with diesel in various proportions it would make the world wonder with its Eco-friendly nature. Biodiesel is nothing but long-chain alkyl esters which is obtained from animal fat and plant seeds. They are regarded as a carbon sink as they absorb $78.5 \%$ of carbon in the atmosphere as they burn and even considered as cleaner than fossil fuels [13]. The considerable amount of studies have been conceded on the effect of biodiesel on engine performance and combustion features. The present study is focusing on the effect of biodiesel in the diesel engine. Based on this work a detailed literature review has been carried out.

\section{MATERIALS AND METHODS}

Eucalyptus oil is the common term for purified oil from the leaf of Eucalyptus, a plant native of Australia and cultivated universally. Eucalyptus oil has an account of extensive claim, as a pharmaceutical, repellent, antiseptic, fragrance, flavoring and industrial usages. The greeneries of particular Eucalyptus species are steam purified to extract eucalyptus oil [14]. Eucalyptus oils are characterized by three extensive types conferring to their arrangement and mainly used for perfumery, medicinal and industrial[15].

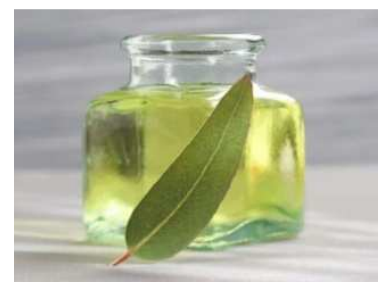

Figure 1: Eucalyptus Oil

The Eucalyptus oil is mixed with the diesel fuel in following proportions to evaluate the performance, pollutant and combustion features of the CI engine.

- $\quad$ B10 - $\quad 10 \%$ of Eucalyptus Oil $+90 \%$ of Diesel

- $\quad$ B20 - $\quad 20 \%$ of Eucalyptus Oil $+80 \%$ of Diesel

- $\quad$ B30 - $\quad 30 \%$ of Eucalyptus Oil $+70 \%$ of Diesel

\section{EXPERIMENTAL SETUP}

Comparing the properties of neat diesel and Eucalyptus Oil and then blending the Eucalyptus Oil with neat diesel of about $10 \%$ and then repeating the same procedure with this some of characteristics is to be change, comparing that characteristics with neat diesel and then blending with $10 \%$ with neat diesel and repeating the same procedure and calculating the same characteristics. Fuel properties are listed in table.1

Table 1: Fuel Properties

\begin{tabular}{|l|c|c|}
\hline \multicolumn{1}{|c|}{ Properties } & Diesel & Eucalyptus Oil \\
\hline Density $\left(\mathrm{kg} / \mathrm{m}^{3}\right)$ & 810 & 930 \\
\hline Viscosity $(\mathrm{cSt}) @ 40$ & 2.5 & 3.0 \\
\hline Lower heating value $(\mathrm{kJ} / \mathrm{kg})$ & 45600 & 44100 \\
\hline Flash point $\left({ }^{0} \mathrm{C}\right)$ & 58 & 93 \\
\hline Cetane number & 48 & 52 \\
\hline Auto ignition temperature $\left({ }^{0} \mathrm{C}\right)$ & 250 & $300-325$ \\
\hline
\end{tabular}


Table 2: Engine Specifications

\begin{tabular}{|l|c|}
\hline \multicolumn{1}{|c|}{ Make } & \multicolumn{1}{c|}{ TV-1, KIRLOSKAR } \\
\hline Power \& Speed & 3.5kW, 1500rpm \\
\hline Type of Engine & 4stroke, DI and Single Cylinder \\
\hline Compression Ration & \multicolumn{1}{c|}{ 16.5:1 } \\
\hline Boreand Stroke & \multicolumn{1}{|c|}{ 200 $110 \mathrm{~mm}$} \\
\hline Loading Type & Eddy Current Dynamometer \\
\hline Cooling Type & Water \\
\hline Fuel Pressure & \multicolumn{1}{|c|}{} \\
\hline
\end{tabular}

The experimental set up comprises of a 4 stroke diesel single cylinder engine and an alternator. The load is organized by the load chamber which triggers the alternator for put on load over the engine. Airflow sensor measures the quantity of air in use. Fuel interpretations are measured by the aid of a fuel sensor. All these measurements are delivered as input to the data acquisition system. AVL 444 gas analyzer is utilized to quantify the emissions from the exhaust pipe.

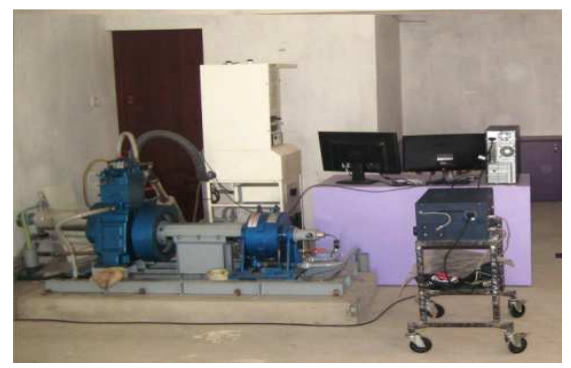

Figure 2: Experimental Engine Set-up

\section{RESULTS AND DISCUSSIONS}

\section{Brake Specific Fuel Consumption}

The outcome for the dissimilarity in the BSFC is displayed in figure 3. For all the fuels, the BSFC decreases with the rise in load. The smallest BSFC is $0.25 \mathrm{~kg} / \mathrm{kWh}$ for diesel, $0.26 \mathrm{~kg} / \mathrm{kWh}$ for B10, $0.37 \mathrm{~kg} / \mathrm{kWh}$ for B20 and 0.42 $\mathrm{kg} / \mathrm{kWh}$ for $\mathrm{B} 30$ in $100 \%$ load condition. The higher BSFC in the event of B30 is owing to their lower energy content, lower calorific value and higher specific gravity matched to diesel.

\section{Brake Thermal Efficiency}

The dissimilarities of BTE for varied load conditions are revealed in figure 4. Here, as the graph clearly shows that the B10 and B20 have an upper BTE than the conventional diesel at any load condition especially B20. This graph also displays that the BTE rises as the load is increased for any fuel. By this graph, it clearly shows that B20 Biodiesel has an upper brake thermal efficiency equated to the diesel.

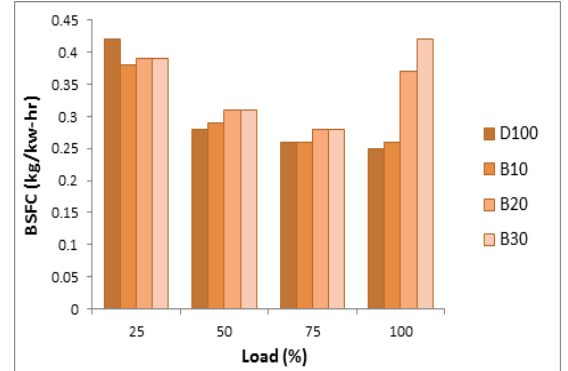

Figure 3: BSFC vs. Load

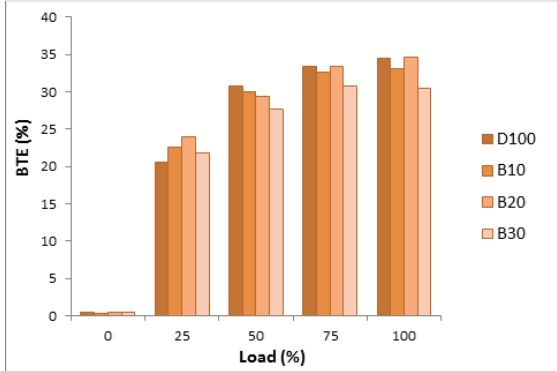

Figure 4: BTE vs. Load 


\section{Hydrocarbon Emission}

Hydrocarbons (HC) are the consequence of incomplete combustion of Hydrocarbon fuel. The fuels with high volatility tend to undergo incomplete combustion. Here, as the graph clearly shows that the B10, B20, and B30 have a lower HC emission than the conventional diesel especially at full load. By this graph, it clearly shows that our B20 Biodiesel has low HC emission compared to the conventional diesel at full load condition.

\section{Carbon Monoxide Emission}

Here, as the graph clearly shows that the B20 biodiesel has a lower CO emission at least 5.3\% than the conventional diesel as the load is increased gradually. By this graph, it clearly shows that B20 Biodiesel has low CO emission compared to the conventional diesel. The reason for low $\mathrm{CO}$ emission from the biodiesel is that they contain high oxygen content.

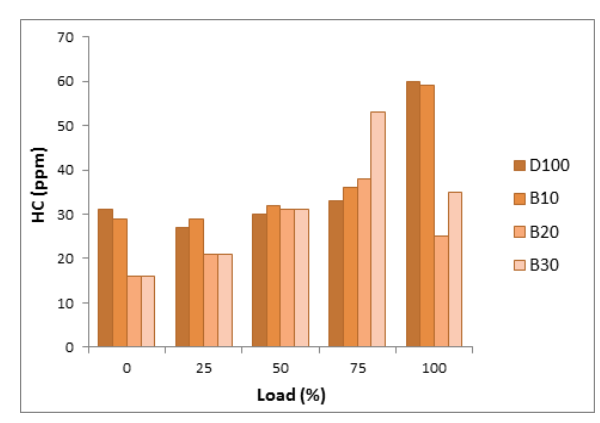

Figure 5: HC vs. Load

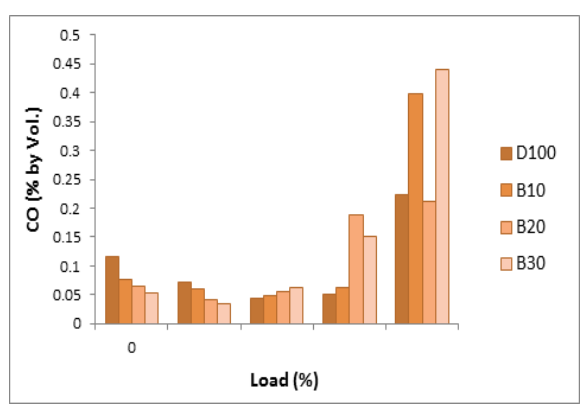

Figure 6: CO vs. Load

\section{Oxides of Nitrogen}

This graph shows the Oxides of nitrogen $\left(\mathrm{NO}_{\mathrm{x}}\right)$ comparison between the conventional Diesel, B10, B20, and B30. Here, as the graph clearly shows that the $\mathrm{B} 20$ and $\mathrm{B} 30$ have a lesser $\mathrm{NO}_{\mathrm{x}}$ emission less than the conventional diesel by $16 \%$ and $8.4 \%$ respectively at $75 \%$ load and $14.4 \%$ and $8.9 \%$ respectively full load condition.

\section{Smoke Opaqueness}

Figure 5 shows the assessment of Smoke opacity at dissimilar loads for diesel, B10, B20 and B30 biodiesel blends. The trial results display that the Smoke opacity increases when the load rises. For all the load conditions diesel has less smoke than other biodiesel blends. Smoke opacity surges with an increase in brake power.

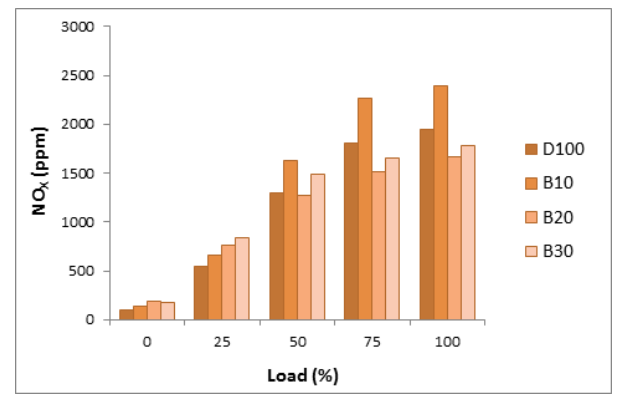

Figure 7: $\mathrm{NO}_{\mathrm{X}}$ vs. Load

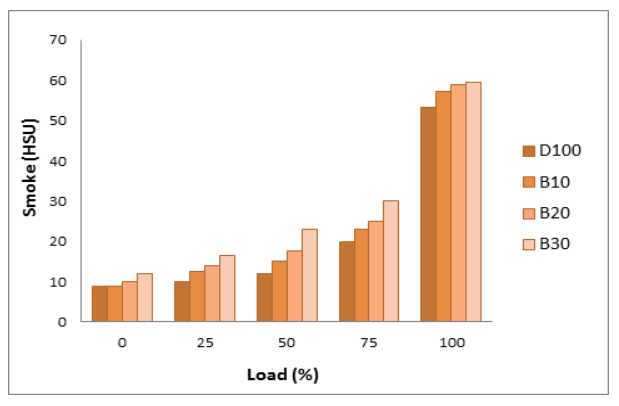

Figure 8: Smoke vs. Load 


\section{Cylinder Pressure}

The Cylinder pressure rise for Diesel, B10, B20, and B30 at maximum load conditions is shown figure 4. It displays the Cylinder pressure increase for B20 is $2.11 \%$ higher than diesel in $75 \%$ load condition. The supreme rate of pressure increase was found to be greater for B20 Biodiesel at high engine loads.

\section{Heat Release Rate}

Figure 6 shows the assessment of HRR at full load condition for diesel, B10, B20 and B30 Biodiesel blends. The trial results display that the HRR increases when the injection pressure is retarded and declines when the injection pressure is advanced. The lesser HRR is observed at $75 \%$ of the load for all fuels. The HRR at $75 \%$ of the load for Biodiesel B20 is closer to diesel. B10 and B30 Biodiesel have lower HRR than diesel due to the lesser release of the temperature to the exhaust, which decreases the heat release rate.

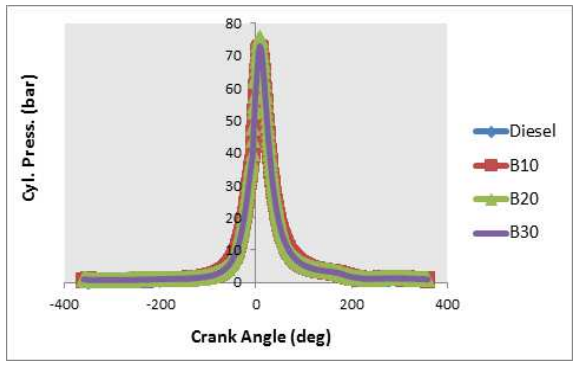

Figure 9: Cylinder Pressure vs. Crank Angle

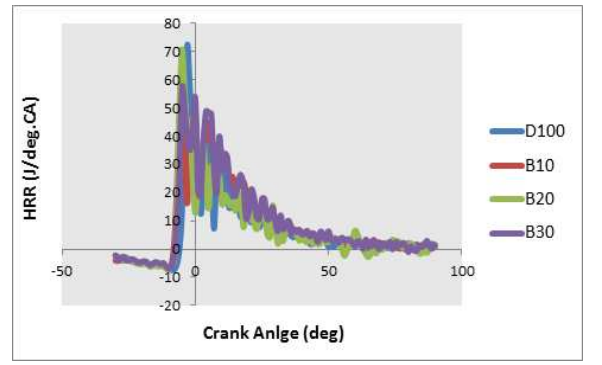

Figure 10: HRR vs. Crank Angle

\section{CONCLUSIONS}

The present experimental investigation has dispensed with the making of biodiesel from eucalyptus, measuring the fuel properties and performance assessment on blends of biodiesel at various loads. The fuel properties like density, viscosity, flash point and calorific value of all the blends are related to diesel and hence diesel may be well substituted by biodiesel in the future. The lower efficiency may be owing to lesser volatility, high viscosity and density of the mixture of eucalyptus-oil and diesel, which disturbs mixture creation of the fuel and thus clues to good combustion. The testing was carried out with dissimilar factors at several loading circumstances. The study results pointy out that, the eucalyptusoil can be straightly utilized in a $\mathrm{CI}$ engine as an outcome of its distinctive chemical properties. Based on the trial outcomes the subsequent assumptions were made. The $20 \%$ of eucalyptus-oil $+80 \%$ of diesel blend exhibited considerably similar BTE and BSFC with diesel. The $\mathrm{CO}, \mathrm{HC}$, and $\mathrm{CO}_{2}$ releases level have been significantly condensed for the mixture of eucalyptus oil and diesel equated with diesel at full load. On the other hand, a mixture of eucalyptus oil and diesel displays a progressive level of $\mathrm{NO}_{\mathrm{X}}$ emission equated with diesel. It was decided that $\mathrm{CO}, \mathrm{HC}$, and $\mathrm{CO}_{2}$ emission lessening is probably at the cost of progressive $\mathrm{NO}_{\mathrm{X}}$ attained from the mixture of eucalyptus oil and diesel used in a $\mathrm{CI}$ engine with no alterations.

\section{REFERENCES}

1. Karikalan, L., Chandrasekaran, M. and Sudhagar, K., 2013. Comparative studies on vegetable oil usage in CI engines as an alternative to diesel fuel. IREME Journal, 7(4), pp.705-715.

2. Prabhahar, M., Manohar, R. M. and Sendilvelan, S., 2012. Performance and emission studies of a diesel engine with Pongamia methyl ester at different load conditions. International Journal of Engineering, Research and Applications, 2(3), pp.2707-12 
3. Vashist, D. and Ahmad, M., 2011. A comparative study of castor and jatropha oil source and its methyl ester test on the diesel engine. International Journal of Engineering, science and technology, 3, pp.4765-4773

4. Rahman, K. M., Mashud, M., Roknuzzaman, M. and Al Galib, A., 2010. Biodiesel from Jatropha oil as an alternative fuel for diesel engine. International Journal of Mechanical \& Mechatronics (IJMME-IJENS), 10(3), pp.1-6

5. Agarwal, A. K. and Das, L. M., 2001. Biodiesel development and characterization for use as a fuel in compression ignition engines. Journal of engineering for gas turbines and power, 123(2), pp.440-447

6. Patel, S. N. and Kirar, R., 2012. An experimental analysis of diesel engine using biofuel at varying compression ratio. International Journal of Emerging Technology and Advanced Engineering, 2(10), pp.385-391

7. Ramadhas, A. S., Muraleedharan, C. and Jayaraj, S., 2005. Performance and emission evaluation of a diesel engine fueled with methyl esters of rubber seed oil. Renewable energy, 30(12), pp.1789-1800

8. Karikalan, L. and Chandrasekaran, M., 2013. Investigation on emission characteristics of CI Engine using vegetable oil with SCR technique. International Journal of Renewable Energy Research (IJRER), 3(4), pp.969-975.

9. Prasad, C. S. N., Reddy, K. V. K., Kumar, B. S. P., Ramjee, E., Hebbel, O. D. and Nivendgi, M. C., 2009. Performance and emission characteristics of a diesel engine with castor oil. Indian Journal of Science and Technology, 2(10), pp.25-31.

10. Sharma, Nikunj. "Algae an Alternative Source of Biodiesel."

11. Vashist, D. and Ahmad, M., 2012. Comparative Study of Performance and Emission Characteristics of a Diesel Engine Fueled by Castor and Jatropha Methyl Ester with the Help of T Test. International Journal of Automotive Engineering, 2 (2), pp.6167

12. Navindgi, M. C., Dutta, M. and Kumar, B. S. P., 2012. Performance evaluation, emission characteristics and economic analysis of four non-edible straight vegetable oils on a single cylinder CI engine. ARPN journal of Engineering and Applied Sciences, 7(2), pp.173-179.

13. Deshpande D. P., Urunkar Y. D. and Thakare P. D., 2012. Production of Biodiesel from Castor Oil using acid and Base catalysts. Research Journal of Chemical Sciences, 2(8), pp.51-56

14. Senthilkumar, P., and G. Sankaranarayanan. "Production of Waste Polyethylene bags in to Oil and Studies Performance, Emission and Combustion Characteristics in DI Diesel Engine."

15. Karikalan, L. and Chandrasekaran, M., 2015. Karanja Oil Biodiesel: A Potential Substitution For Diesel Fuel In Diesel Engine Without Alteration. ARPN Journal of Engineering and Applied Sciences, 10(1), pp.152-163

16. Tamilvendhan, D. and Ilangovan, V., 2011. A performance, emission and combustion investigation on hot air assisted eucalyptus oil direct injected compression ignition engine. Modern Applied Science, 5(4), p.53-62

17. Devan, P. K. and Mahalakshmi, N. V., 2009. A study of the performance, emission and combustion characteristics of a compression ignition engine using methyl ester of paradise oil-eucalyptus oil blends. Applied Energy, 86(5), pp.675-680. 